\title{
Charity flea markets - an amalgamation of product philanthropy and volunteering
}

\author{
Sandra Stötzer ${ }^{1}$ (D) $\cdot$ René C. Andeßner ${ }^{1} \cdot$ Sarah Scheichl ${ }^{1}$
}

Received: 1 November 2019 / Accepted: 19 December 2019 / Published online: 9 January 2020

(C) The Author(s) 2020

\begin{abstract}
This paper offers one of the first efforts at exploring the role of charity flea markets as a fundraising practice used by nonprofits to mobilize various resources like individual and corporate in-kind giving and volunteering in an unique event setting. With the support of volunteers, nonprofits generate cash by reselling product donations and by catering. As an innovative contribution to the so far limited research on flea markets and in-kind giving, our study uses an explorative case study approach based on guided interviews with Austrian flea market operators. The purpose of the case studies is to examine the specifics, benefits, challenges, and prospects of this underexplored funding instrument. Our findings contribute to an enhanced understanding of both charity flea markets and nonprofits resource management and can assist charities in processing inkind donations effectively and sustainably.
\end{abstract}

Keywords Flea markets · In-kind giving · Product philanthropy · Second-hand markets · Volunteering

\section{Introduction}

All kinds of organizations face the basic management problem of how to get the resources necessary to finance their activities and achieve their objectives. With this in mind, nonprofit organizations (NPOs) are distinct from other organizations as they typically rely on multiple sources of funding including, e.g., membership dues, private and corporate giving, government grants and contracts, special events, or earned income like revenues from sales and fees for services. However, not only monetary resources but also in-kind resources and labor (paid and voluntary) are essential for many NPOs in order to sustain the achievement of their mission in

Sandra Stötzer

sandra.stoetzer@jku.at

1 Johannes Kepler University Linz, Institute of Public and Nonprofit Management, Altenberger Straße 69, 4040 Linz, Austria 
terms of specific public benefit purposes like, for instance, helping the needy (Anheier 2014; Kearns et al. 2014).

Although research on fundraising and cash giving is extensive, a substantial research gap exists with respect to in-kind or noncash giving (Gazley and Abner 2014; Gray 2007). This paper seeks to contribute to addressing that lacuna by investigating a specific kind of fundraising practice: charity flea markets (CFMs). We distinguish conventional flea markets constituted by a multitude of individual vendors, and CFMs organized by a single nonprofit organization (NPO). Like charity shops, NPOs operate such second-hand markets to support their mission. With the assistance of volunteers, NPOs generate cash by reselling in-kind donations from both individuals and corporations. Existing academic literature on second-hand markets in general and flea markets in particular is sparse, too (Chattoe 2000; Hansson and Brembeck 2015; Mitchell et al. 2009; Sherry Jr 1990a).

Given the lack of research on in-kind donation management and flea markets, this study uses a deliberately explorative case study approach. Based on a multidisciplinary literature review bundling existing knowledge on second-hand markets, we investigate ten cases of Austrian NPOs that organize CFMs on a regular basis. Informed by a qualitative methodology, semi-structured guided interviews aimed at capturing the experiences and understandings of those representatives responsible for operating the markets, in order to explore the purposes, benefits and challenges of this funding instrument. The following research questions guided our inquiry:

- Which goods (product donations) typically are offered and sold at CFMs? Who are in-kind donors and flea market customers?

- What are the main challenges related to organizing CFMs and processing in-kind gifts?

- How do NPOs assess the benefits and future perspectives of CFMs?

The aim of this qualitative research project is to provide a comprehensive image of the processes related to organizing CFMs as well as to explore critical success factors. An in-depth examination of the benefits and challenges of CFMs can support a nonprofit's decision for or against this exceptional means of raising funds. Additionally, our study intends to enhance understanding of the advantages and drawbacks of in-kind donations and to shed light on the question how product philanthropy fits into an operational approach to managing NPOs' organizational resources.

The contributions of this article are fourfold. First, we provide a consolidated overview of existing knowledge on second-hand markets. Therefor the paper brings international research on charity shops and flea markets together and draws insights from these contexts applicable to CFMs. Second, the limited scholarship on flea markets is often characterized by a sociological, anthropological or consumer behavior view and mainly focuses on conventional flea market settings. To the best of our knowledge, this is the first study to explore flea markets organized by NPOs and to investigate this kind of market from a nonprofit management angle. Thus, our paper complements the literature on nonprofit management in general and on giving and volunteering in particular. Third, our article offers a working definition of CFMs derived from the literature review and our case studies. Finally, our findings are of both practical and theoretical significance as they enhance understanding of product donations as well as CFMs and can assist NPOs in organizing such markets, targeting 
different in-kind donor groups and other supporters, and processing noncash contributions effectively. In addition, second-hand markets can not only serve as a fundraising instrument but also as a means to reduce waste and protect natural resources as well as to promote awareness for social and ecological causes. Besides, our empirical observations serve as an inspiration for some theoretical reflections regarding NPOs' resource management. Organizing CFMs typically involves combining multiple resources, like individual and corporate giving (both cash and especially in-kind), revenues from catering and sales of donated goods, and both regular and episodic volunteering; this mix represents an amalgamation of heterogeneous resources that have to be suitably coordinated and sustainably managed.

The remainder of the paper proceeds as follows. First, we review literature on inkind donations, charity shops, and flea markets to illustrate the state-of-the-art and to provide context for our investigation. Second, the study's methodology is outlined. Third, we present our findings on selected CFMs, and subsequently discuss them and their implications for nonprofit flea market operators. Finally, some concluding remarks and avenues for further research are offered.

\section{Literature review}

"[A]ccumulating possessions is a common human passion, especially in our acquisitive society" (Scitovsky 1994, p. 35). In the era of consumer disposables, many people adopted a culture of buy and discard, often replacing the former ethos of make do and mend (Horne and Maddrell 2002). However, the evolution of such a "throw-away" society is accompanied by a growth of the second-hand sector (especially in Western Europe and North America). The trading of unwanted goods and second-hand markets - like retro shops, vintage boutiques, Internet barter as well as auction sites, garage or car-boot sales and flea markets - have been prevalent throughout consumer history, but are booming in the last decades. Many consumers of post-industrial societies are now in an endeavor to sell, barter or donate used objects and to reuse, recycle, upcycle and reduce. Reasons for these trends are manifold: a widespread need to de-clutter over-filled homes and to handle the overflow of commodities, aspects of socializing, decorating homes, economic hardship, preserving old things, and finally yet importantly, challenges of social inequalities and environmental degradation involving a popularization of ethical and environmental concerns (Appelgren and Bohlin 2015a, b; Bianchi and Birtwistle 2012; Duffy and Hewer 2013; Roux and Guiot 2008).

The term "second-hand" broadly refers to all kinds of used objects exchanged within commercial contexts. Such goods are not any longer simply associated with low status as growing parts of middle class consumers are adopting second-hand practices. Second-hand goods form a hybrid category of things: they combine characteristics of both commodities and gifts and have commercial as well as social value (Appelgren and Bohlin 2015a, b). From an economic viewpoint, second-hand markets can generate employment and income, mitigate unequal income distribution und stimulate the economy as they enable people to replace their used goods with new ones. Altogether, they facilitate getting rid of unwanted objects, just as much as they do stimulate hoarding (Scitovsky 1994). 
Consumers have three choices of product disposition: keep it, dispose of it temporarily, and dispose of it permanently (Mitchell et al. 2009). When disposing surplus belongings consumers can give them away to family or friends, sell them through second-hand shops or eBay, donate them to charity or throw them away into rubbish bins (Bianchi and Birtwistle 2012). Many people do not consider throwing away their excess items as an attractive option, but have a desire to handle their items in an ethically acceptable manner (Appelgren and Bohlin 2015a; Lovatt 2015). This common attitude as well as the abundance of surplus goods provides a niche for second-hand markets and charities. Many NPOs operate charity shops, jumble sales or flea markets in favor of local causes and interests. They collect donations of (used) goods, resell them at a good price, and use the proceeds to finance their services and support their missions (Chattoe 2000; Gray 2007; Horne and Maddrell 2002; Mitchell et al. 2009). Such contributions of personal items are increasingly important to many NPOs. However, in-kind donations do not only constitute important resource streams, but can also create challenges (Islam 2013). As second-hand markets rest upon the resale of noncash contributions, the following section will shortly summarize basics concerning in-kind donations, before we summarize the state of knowledge about charity shops and flea markets.

\subsection{In-kind donations}

In-kind donations or gifts-in-kind are "a form of non-cash philanthropic contributions" (Lee 2015, p. 1). In-kind giving comprises both direct and indirect donations of products or services of all kinds. In-kind donations and volunteering are intertwined as product donations typically create opportunities for volunteering. Most categorizations of in-kind donors refer to individuals or households (individual in-kind giving) and to businesses (corporate in-kind giving); but also government agencies can offer gifts-in-kind (government in-kind giving). Donors can donate products directly to recipient NPOs that use them for their mission-directed activities or indirectly to NPOs that pass them on. Existing research mainly focuses on corporate in-kind giving (including product donations, employee volunteering, and pro bono services). Product donations comprise all kinds of goods which may either be durable, need storage space and maintenance or are perishable and must be used quickly after receipt (Gazley and Abner 2014; Gray 2007; Islam 2013). Motivations of businesses to donate products to charity are both instrumental and altruistic (Lee 2015). In-kind giving is cost effective for corporations as it does not require cash resources, instead they can donate their products, services or people and satisfy their stakeholders' expectations. In-kind giving provides opportunities for disposal of surplus inventories, reducing disposal costs (of e.g., mislabeled items) and for employee engagement, tax deduction as well as image enhancements. Therefore, product donation programs are increasingly popular (Islam 2013; Ross and McGiverin-Bohan 2012).

Though money is the most efficient gift, in-kind donations are the fastest growing segment of philanthropic giving and an essential source for many NPOs. On the one hand, they convert donated goods by reselling them (to customers or commercial brokers). Thus, they can use the proceeds to fund services and supplement their cash resources. On the other hand, donations are used by NPOs themselves or by their beneficiaries. However, in-kind gifts are accompanied by organizational capacity 
challenges. NPOs need to expend resources to transport, store, and process them. Some charities receive more goods than they could use or damaged items or even "junk donations" entailing costs. Others lack adequate logistics infrastructure like storage space or means of transportation, and many are facing volunteer shortages (Gazley and Abner 2014; Gray 2007; Islam 2013; Lee 2015). Hence, product donations do not always meet organizational needs and can "occupy already scarce (...) capacities and consume valuable staff time and money to manage" (Islam 2013, p. 2). In sum, in-kind donations can be valuable, valueless, and negatively valued (Sherry Jr 1990b). Consequently, NPOs should reflect whether to accept or deny certain goods. However, rejecting inappropriate donation offers can put future gifts at risk (Islam 2013).

\subsection{Charity shops}

Numerous NPOs (e.g., Oxfam, The Salvation Army, Goodwill, Habitat for Humanity, Red Cross, Caritas or local ministries) operate retail stores commonly referred to as "charity shops" in the UK, as "thrift stores" in the US or as "Sozialmärkte" in Austria. They seek second-hand goods (and partially food), sell them and thus convert these goods into cash, and use the gained proceeds to support their missiondriven activities. While charity shops and thrift stores mainly seek and sell nonfoods, "Sozialmärkte" often sell (primarily) food as well as durable goods (Horne and Maddrell 2002; Islam 2013; Lienbacher 2013; Lovatt 2015; Mitchell et al. 2009; Montgomery and Mitchell 2014; Shearer and Carpentier 2015). In the US alone, estimates account for over 25,000 thrift stores, and in the UK, there exist more than 6000 charity shops (Islam 2013; Lienbacher 2013). Trends like shrinking household and family sizes (with few offspring to leave possessions to), increasing house sizes filled with plenty of things, and shortened product life cycles are beneficial conditions for charity shops and foretell a further boom of available second-hand merchandise. At the same time, the number of NPOs increases and forprofits are turning to the resale industry, too, thereby intensifying competition for donated goods. Increased competition influences disposal behavior and the awareness of the value of used goods. In times of online auctions, eBay, and other platforms many people first check their options to make money out of their objects and not until then donate the unsold remainder to a thrift store (Mitchell et al. 2009).

Charity shops have unique cost and price setting particularities. Such stores are different to "high street shops" in several ways (Chattoe 2000; Lienbacher 2013; Montgomery and Mitchell 2014):

- Their merchandise mainly comes from consumers who donate used items. Therefore, choice is limited and both the nature and level of supply are hard to influence. Second-hand donations imply an uncertainty concerning quality. This places constraints on pricing: used goods have to be sold for (considerably) less than new products; sometimes only symbolic prices are charged.

- Mainly unpaid volunteers staff them, thus opening hours are often comparatively restricted. This workforce has to handle shelf restocking, presenting goods, monitoring sale, negotiating prices, taking money, and providing information. In addition, working practices are partly different from those in first-hand markets, like, e.g., collecting goods from donors, sorting, identifying, testing, repairing, and 
cleaning items, recycling or disposing unwanted stuff. Some donations can pose further problems for resale, like electrical equipment needing skilled testing or bulky commodities complicating handling.

- They sometimes do not have to pay shop rental and often receive public support and/or tax relief.

- Further features relate to the store's overall objectives, as profit is just a means of facilitating charitable work, and the identities of their customers; many customers favor low prices, the possibility of bargains, and browsing through the shop's choice. Besides, some stores, especially "Sozialmärkte" offering mainly groceries (and counteracting food waste as well as poverty), deliberately target a low-income customer group and issue proofs of entitlement to shop.

In sum, the operators of such retail stores have to compete in both donor and buyer markets, complicating the marketing challenge. In addition, they are interacting with the waste sector determining the market-clearing prices of recycled merchandise. If a charity shop succeeds in improving donation activity (i.e., collecting more and better goods) this could advance the shop's resale performance (Mitchell et al. 2009; Montgomery and Mitchell 2014). In this regard, narratives geared to the target group can encourage people to buy as well as to donate. Creating an image of "how the lives of objects might be extended in second-hand markets, can act as an incentive for people to donate things to charity shops" (Lovatt 2015, p. 27). Besides competition for donors and consumers, charity shops also compete for (largely female) volunteers (Horne and Maddrell 2002).

Literature does neither tell much about the identity, motivations, and shopping experiences of charity shops' customers nor about the work experiences and motivations of volunteers. Roux and Guiot 2008 present some insights concerning the motives for second-hand shopping in general. Hence, motives for buying second-hand products combine several economic and recreational dimensions. The second-hand channels themselves are sources of interest to buyers. More insights are available concerning donors. Montgomery and Mitchell 2014, for instance, investigate both donor and buyer activity as many people shop at and donate to thrift stores at once. They classify their respondents as net shoppers (i.e., shopping more than donating) or net donors (vice versa) and find significant differences with respect to age, employment and marital status as well as education. Although older and employed persons generally seem attractive to charities, their study shows, inter alia, that younger adults (18-34-yearolds), part-time employees and unemployed people are more likely to be net donors than older or full-time employed persons. Besides, Bianchi and Birtwistle (2012) explore antecedents of sustainable clothing disposal behavior and show that general consumer recycling behavior is significantly related to donating to charities. They also identify an indirect effect on charitable donating as consumer awareness of the environment is positively related to consumer recycling behavior. Finally, Mitchell et al. (2009) report the following top reasons for donating: seasonal cleaning, need to free up space, and the desire to help other people. This indicates that self-interest donating motivations trump altruistic motivations among donors of used merchandise. Women are significantly more likely to donate to charity shops. Concerning information sources for in-kind donors, location visibility, past experiences, and recommendations from friends and family are most important. Thus, relationship marketing and 
word-of-mouth communication of satisfied supporters is vital and should be encouraged. Mitchell et al. (2009) therefor suggest "teaching donation collection and store personnel the importance of their interaction with all donors and clients; recruiting donors to be volunteers, (...); following up with personal thanks (...); promoting the positive outcomes of donations such as the number of needy helped (...); and making each donor interaction personally satisfying" (p. 266). When selecting a charity most people need confidence that their donations are properly used. Besides, they highlight the convenience of donation drop-off locations and the NPO's service mission. As inconvenient donating logistics are a barrier to giving, NPOs should maintain a visible presence in their community for drop-off, create awareness among possible donors, anticipate when cleaning will occur (e.g., after gift-giving holidays), facilitate easy donations, and organize well-timed (seasonal cleaning) promotions (primarily targeted to women). In the UK "bag drops" proved to be successful: NPOs deliver bags (that people can fill with goods) to households and collect them later. Lovatt (2015) highlights another factor influencing donations to charity shops: "a sense of wanting things which were no longer wanted or needed (...) to be of use to, or valued by, other people" (p. 22). Many people prefer a future re-use of objects, some out of environmental considerations, others because they would like to provide a future for valued items, e.g., former possessions of family members who died.

Overall, for charity shop customers the low prices and the "good cause" are enticing. Besides, the perceived experience of shopping influences many buyers' shop choice. The specific character and "Aladdin's Cave appeal" of charity shops can be an advantageous unique feature. Insofar a withdrawal of bargain opportunities could reduce perceived fun of some shoppers. Moreover, Chattoe (2000) explicitly cautions against an increased "professionalism" which may not improve profitability but could affect the identity and motivations of the shop's clients and thus discourage the existing customer base.

\subsection{Flea markets}

Multitudes of flea markets exist around the world. Flea markets are a retailing institution characterized by basic exchange mechanisms (like countertrade). They constitute alternative marketplaces for a variety of low-cost goods or for collectibles like antiques. Additionally, flea markets provide a special shopping experience vividly contrasting with that offered in mainstream malls or conventional department stores. Besides the particular nature of real estate of such markets, main differences relate to price, finding used merchandise, and the possibility to negotiate (Petrescu and Bhatli 2013; Sherman et al. 1985; Sherry Jr 1990a; Watt and Dubbeld 2016; Appelgren and Bohlin 2015a; Hansson and Brembeck 2015).

Flea markets are "a fascinating combination of formal and informal, economic and festive dimensions of marketplace behaviors" (Sherry Jr 1990b, p. 177). For Hansson and Brembeck (2015) they are foremost "places of commerce and exchange of second hand goods" (p. 118), even though various other forms of flows or circulatory logics are simultaneously going on. Sherman et al. (1985) define this part of the underground economy as an "organized market where vendors bring a wide variety of goods to sell" (p. 205). Thus, flea markets are at once manifestations of the informal and formal economies (de Bruin and Dupuis 2000; Sherry Jr 1990a). Informal retailing is 
characterized by a lack of permanence and consistency regarding location, frequency, pricing structure or merchandise assortment (Mhango and Niehm 2005).

The work of flea market dealers comprises premarket activities like amassing inventory and the logistics of line-up and setup. Some traders develop an "instinctive knowledge" about marketable objects and some invest time refurbishing items. Setting up a flea market stall is laborious. Many dealers enlist the assistance of family members for setting out tables or tarpaulins, positioning umbrellas and canopies, unloading and unpacking boxes, unwrapping and displaying objects and running their stall. After the market, dealers have to invest time and labor in packing up. Many vendors prefer small and high turnover items they can easily transport and so rather logistical considerations than consumer preferences dictate assortment. Dealers often pursue both economic and non-economic goals like sociability as many regard it as a nice leisure time activity and enjoy talking, laughing, and dickering with clients as well as fellow dealers in a friendly atmosphere (de Bruin and Dupuis 2000; Hansson and Brembeck 2015; Sherman et al. 1985; Sherry Jr 1990a; b; Watt and Dubbeld 2016).

The consumer base of flea markets comprises all kinds of people. Low prices, a large product assortment for all tastes, as well as the special mix of shopping, social interaction, and entertainment attracts both locals and tourists. Lower income people try to satisfy their consumption needs while high-income visitors look for hobbyrelated items or hunt for "treasures". Collectors, hobbyists and antique dealers are recurrent visitors. Many individuals consider flea markets as enjoyable places to shop, to bargain, to socialize or to discover products that are no longer available new. Hence, besides pragmatic needs or economic necessity (as a way to make ends meet), this form of consumption is driven by consumer dispositions like curiosity, surprise, and pleasure (Appelgren and Bohlin 2015b; Hansson and Brembeck 2015; Petrescu and Bhatli 2013; Sherman et al. 1985; Sherry Jr 1990a). Some visitors also stress "issues of sustainability: 'Recycling is good' (...) It's environmentally conscious shopping (...). [T] hese people drew on discourses of sustainability to legitimate their consumer practices" (Hansson and Brembeck 2015, p. 113f).

Sherry Jr (1990a) describes the essence of flea markets as follows: "It's an event to go to the flea market" (p. 17). Hence, the flea market experience is more important to most consumers (oscillating "between homo oeconomicus and homo ludens") than product assortment (Sherry Jr 1990b, p. 180). People love the organic and festive atmosphere such colorful markets exude, their affective intensities and "buzz" as well as the particular thrill of search, the joy of unexpected finds and the visual perception of cluttered environments. The intimate, crowded, and interactive atmosphere creates a feeling of community. Thus, such marketplaces provide for the human need of social interaction (Appelgren and Bohlin 2015b; de Bruin and Dupuis 2000; Duffy and Hewer 2013; Hansson and Brembeck 2015; Petrescu and Bhatli 2013). In addition, food sale is contributing to the family atmosphere and an incentive for people to visit flea markets and remain there (Sherry Jr 1990a).

Overall, literature on flea markets focusses on markets with a multitude of individual vendors earning their living or pin money. The few available scientific papers predominantly constitute sociological, ethnographic or anthropological studies analyzing the markets' dynamics as well as shoppers' and dealers' behavior and interaction. Besides, single studies apply an economic and consumer research perspective. To the authors' 
knowledge, so far, no studies on CFMs exist. The next section outlines the methodology employed for exploring this object of investigation to narrow this gap.

\section{Methodology}

Given the lack of research studying CFMs as a fundraising instrument, we opted for an exploratory case study approach (Yin 2018) based upon semi-structured guided interviews with Austrian charity flea market (CFM) operators. This qualitative research method can provide rich insights into our subject and allows an in-depth understanding of the characteristics of CFMs and the associated benefits, challenges, and future perspectives.

After reviewing the flea market landscape in Upper Austria in order to identify possible units of analysis, we selected ten NPOs that organize CFMs on a regular basis. Our selection criteria focused on the type of organization and accordingly the nonprofits' field of activities, their location in diverse districts to incorporate different regional settings, their experience with CFMs, and their willingness to participate. Only one of the contacted charities was not willing to give us an interview and was replaced by another case. Altogether, our sample comprises ten CFMs located in six different districts. We also intended to identify possible differences because of the frequency and type of the markets. Table 1 overviews the cases and their characteristics.

Table 1 Sample of CFMs

\begin{tabular}{|c|c|c|c|}
\hline case & type of organization & regional setting & frequency \& type of market \\
\hline $\begin{array}{l}\text { NPO A } \\
(\mathrm{P} 1)^{\mathrm{a}}\end{array}$ & service organization $^{b}$ & rural area & $\begin{array}{l}\text { annual } \\
\text { indoor CFM }\end{array}$ \\
\hline $\begin{array}{l}\text { NPO B } \\
(\mathrm{P} 2)\end{array}$ & service organization & $\begin{array}{l}\text { hybrid (rural but } \\
\text { part of urban } \\
\text { agglomeration) }\end{array}$ & $\begin{array}{l}3 \text { times a week } \\
\text { indoor CFM }\end{array}$ \\
\hline $\begin{array}{l}\text { NPO C } \\
(\mathrm{P} 3)\end{array}$ & service organization & rural area & $\begin{array}{l}\text { annual } \\
\text { indoor CFM }\end{array}$ \\
\hline $\begin{array}{l}\text { NPO D } \\
(\mathrm{P} 4)\end{array}$ & voluntary fire brigade & rural area & $\begin{array}{l}\text { annual } \\
\text { outdoor CFM }\end{array}$ \\
\hline $\begin{array}{l}\text { NPO E } \\
(\mathrm{P} 5, \mathrm{P} 6, \mathrm{P} 7)\end{array}$ & religious organization & urban area & $\begin{array}{l}\text { annual } \\
\text { indoor CFM (plus several outdoor tents) }\end{array}$ \\
\hline $\begin{array}{l}\text { NPO F } \\
(\mathrm{P} 8, \mathrm{P} 9)\end{array}$ & service organization & rural area & $\begin{array}{l}\text { annual } \\
\text { indoor CFM }\end{array}$ \\
\hline $\begin{array}{l}\text { NPO G } \\
(P 10)\end{array}$ & religious organization & urban area & $\begin{array}{l}\text { biennial } \\
\text { indoor CFM (\& outdoor kids program) }\end{array}$ \\
\hline $\begin{array}{l}\text { NPO H } \\
(\mathrm{P} 11)\end{array}$ & religious organization & urban area & $\begin{array}{l}\text { annual } \\
\text { indoor }+ \text { outdoor CFM }\end{array}$ \\
\hline $\begin{array}{l}\text { NPO I } \\
(\mathrm{P} 12)\end{array}$ & animal welfare organization & urban area & $\begin{array}{l}\text { biennial } \\
\text { indoor }+ \text { outdoor CFM (several tents) }\end{array}$ \\
\hline $\begin{array}{l}\text { NPO J } \\
(\mathrm{P} 13)\end{array}$ & $\begin{array}{l}\text { sports and recreation } \\
\text { club (soccer) }\end{array}$ & rural area & $\begin{array}{l}\text { monthly } \\
\text { CFM under canvas }\end{array}$ \\
\hline
\end{tabular}

${ }^{a}$ In order to ensure anonymity each NPO is referred to by a letter and each interviewee by a number. As interviews were conducted in German, quotes cited in this paper are translations by the authors

b Anheier (2014) terms NPOs like the Rotary Club, the Lions, Kiwanis, etc. as "service organizations" (p. 6) 
From July to October 2018, we interviewed representatives of these NPOs who are responsible for planning and organizing CFMs. The ten semi-structured interviews lasted between 40 and $63 \mathrm{~min}$ and were conducted face-to-face and mainly with one person; in two interview settings, two resp. three persons talked to us as a team of CFM operators. For guidance and comparability, we used a (deductively designed) interview protocol with open-ended questions (see appendix) synthesizing findings of the literature review. All interviews were recorded and transcribed. The authors separately carried out a qualitative content analysis (Krippendorff 2013; Mayring 2010) of the material. Therefore, we coded, paraphrased, and generalized the transcripts, and assigned the generalized statements to the following main categories (which were inductively specified by several sub-categories during the analysis): organization of CFMs, purposes, donors, sort of in-kind gifts, clients, challenges and success factors, volunteers, disposal, benefits, and future perspectives. Besides the interviews as our core research activities, we gathered some further insights through individual participant observations at selected CFMs.

\section{Findings}

\subsection{Purposes, organization and stakeholders of charity flea markets}

The main purpose of CFMs is to raise financial resources for the NPO's mission-driven activities. While service clubs generally pass on the generated surplus to either individuals in need or other organizations supporting specific causes, most NPOs use it to finance specific projects like the acquisition of costly equipment (e.g., for fire service) or renovation of infrastructure (e.g., refurbish a dog house). Such investments often could not be realized without the profits earned by the CFMs. The following statements exemplary illustrate the importance of this fundraising practice:

"For us, the surplus obtained by the flea market actually is our main source of income. Without it we would not exist in our current form" (P4).

"The flea market has by all means great significance for the parish. It's a crucial source of funding for undertakings our parish otherwise could not finance" (P10).

Organizing a CFM involves numerous tasks and efforts. Figure 1 displays a process map systematically encapsulating necessary activities of both CFM operators and volunteers. It comprises core processes, support processes, and management processes. Trade-related core processes include all activities related to handling merchandise like collecting, sorting, and storing in-kind donations as well as presenting and selling goods. If objects remain unsold, operators have either to dispose of them or organize transfer to other (commercial or nonprofit) organizations for further resale or disposal. In addition, there are catering-related core processes involving preparation of sales booths, equipment and meals, selling food and beverages as well as cleaning up after market day. Besides, several support processes are essential for the functioning of a CFM (e.g., promoting the event in advance, assessing the value of goods for sale, organizing entertainment programs, providing security and preserving order, or technical installations for electricity supply). Superordinate management processes ensure 


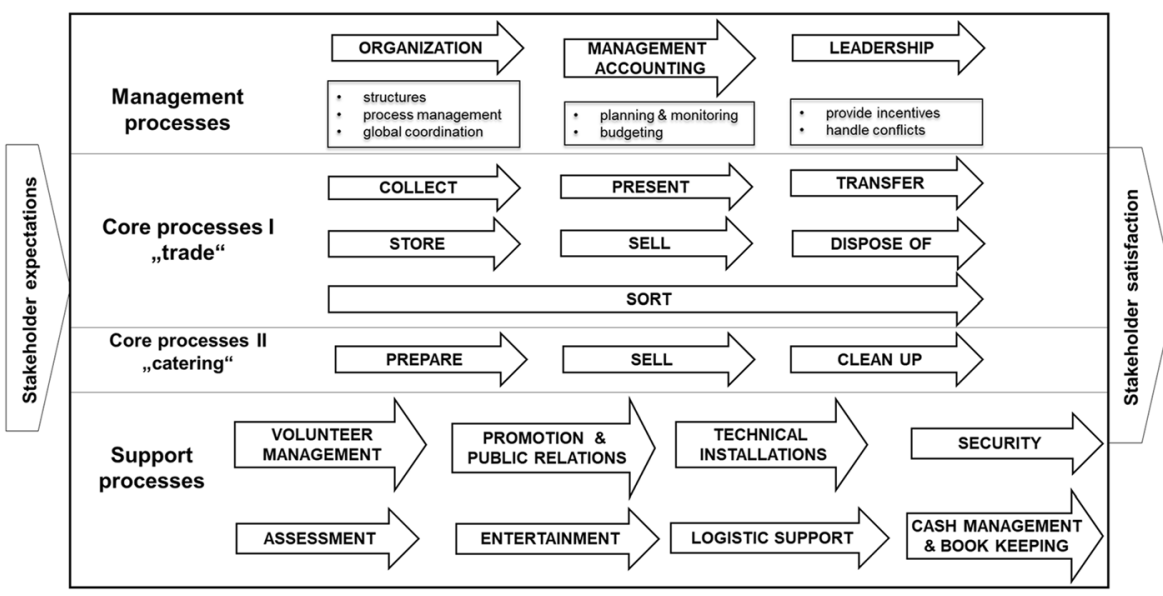

Fig. 1 Process map of CFMs

that all core and support processes timely take place in a coordinated manner. They comprise all necessary activities related to leadership, organization and task management as well as management accounting issues. Tools like checklists or flowcharts can support management processes.

The outlined core and management processes are primarily operated by volunteers and characterized by self-organization. Specialized teams of volunteers carry out different tasks assigned to them. A team leader acting as a coordinator and responsible process owner guides them. These team leaders communicate with the chief team leader or a steering group in charge of global coordination and monitoring. In contrast, support processes typically include several stakeholders in addition to volunteers, like specialized commercial service providers or businesses granting pro bono services. In sum, CFMs involve a multitude of internal and external stakeholders. On the one hand, there are input-related stakeholders (e.g., donors of both goods and cash including individual households, businesses, and other NPOs, or suppliers and service providers), and on the other hand outputrelated stakeholders like customers and other visitors as well as other NPOs, retailers or disposal and recycling companies. Further stakeholders include neighbors of market locations, the media and public sector institutions (e.g., municipalities or tax authorities).

Volunteers evidently are key stakeholders of CMFs. As is known, volunteering appears in different types (cf., e.g., Hustinx 2005; Smith et al. 2016). In the context of CFMs, it seems adequate to distinguish three types we integrated in a shell model displayed in Fig. 2:

- a recurrent long-term and time-consuming commitment,

- a recurrent long-term but less time-consuming commitment, and

- a short-term, episodic commitment possibly focused on one single project.

CFMs typically combine all three types of volunteering characterized by different degrees of commitment. The more a volunteer moves towards the center of the shell model the higher is the intensity of the person's commitment. Chief team leaders, for instance, face the challenge to engage themselves on a long-term and time-consuming basis. They 


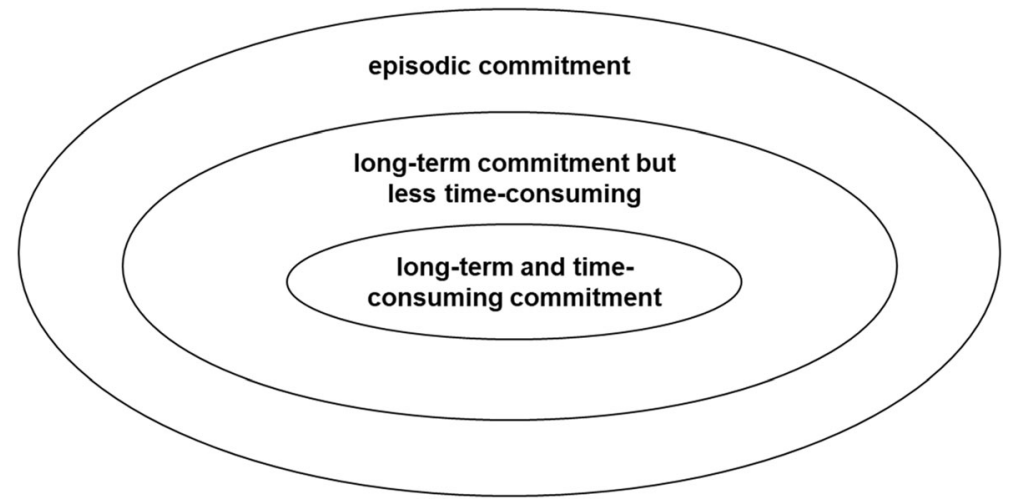

Fig. 2 Shell model of volunteering in CFMs

permanently fulfil their tasks if markets are organized regularly. When follow-up finishes, they at once start preparing the next event. Being a team leader for a single (core or support) process requires a long-term commitment but is less time-consuming. Working as a volunteer exclusively on market day is an example for episodic commitment.

\subsection{Typical donors, in-kind donations and clients}

Both individuals and businesses donate gifts-in-kind to CFMs. Half of the investigated NPOs receive noncash donations only from private citizens who perceive giving as a chance to clear out their belongings and an alternative to littering. A specific group of donors is heirs of real estate intending to empty inherited houses or apartments in order to sell or let them. Corporate in-kind donors often provide single pieces or clear their stock and phase out specific products. We identified no differences in the kind of donations (and neither in donors nor clients, nor in other respects) between the ten cases in relation to their characteristics displayed in Table 1.

The assortment of CFMs is composed of various in-kind donations. NPOs predominantly offer the following product categories for sale:

- all kinds of clothes and textiles like bedding, curtains, table cloths or fabrics in a raw state

- shoes, bags, and other leather goods

- housewares

- decorative items like candles, vases, etc.

- books, games, records, and CDs

- children's toys

- electrical appliances

- $\quad$ sports equipment like bicycles, skis, sportswear, etc.

- antiques, pictures and picture frames

- watches and jewelry

Furniture represents a special case as most respondents only accept small pieces. Large items of furniture occasion high transportation costs and are no longer in demand by the majority of the markets' clientele that is composed of individuals and families as well 
as people of each gender and all age groups. The customer base is heterogeneous and mainly comprises:

- locals appreciating the CFM as a special event;

- people looking for bargains and the unique atmosphere of the CFM;

- consumers of scarce means meeting their everyday needs by cheaply acquiring necessities;

- domestic and foreign resellers.

\subsection{Challenges and success factors}

The interviewees mentioned a variety of challenges related to operating CFMs. They consider meeting these challenges as critical. Figure 3 shows the identified challenges and success factors at a glance.

\subsubsection{Volunteering}

The availability of a sufficient number of volunteers is essential both beforehand, on and after market days. Moreover, CFMs seem to be successful when they adequately link the aforementioned types of volunteering as they rely on different forms and intensities of volunteering. While volunteers who engage themselves only episodically to do project-related work can accomplish certain tasks, other tasks (such as the overall management and coordination of activities or gathering goods) require a regular, longterm, and time-consuming commitment. Such duties also require certain availability in times of common working hours. Thus, mobilizing the generation $60+$ is vital. The NPOs analyzed count on many long-term volunteers supporting their CFMs for many years. Nevertheless, various volunteers already reached old age (between 70 and 80), are partly overcharged by physical labor, and often wonder whether they will find successors when they (have to) cut back their commitment. Besides, half of the interviewees take the view that volunteers need specific talents or skills like sales talent, management skills or experience in public relations.

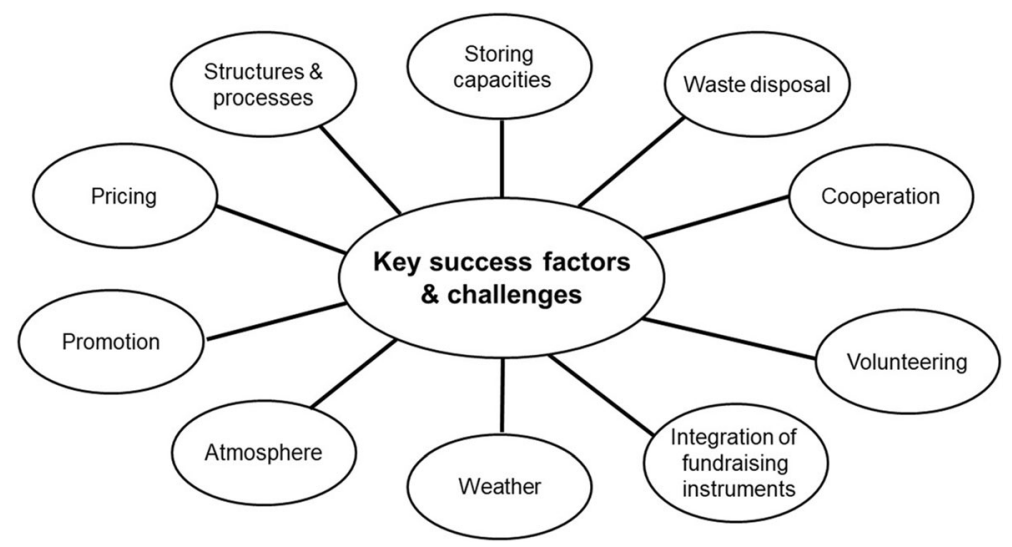

Fig. 3 Operating CFMs - key success factors and challenges 


\subsubsection{Structures and processes}

Creating appropriate structures and processes is critical for CFMs that are characterized by a network organization. According to tasks and product groups, specialized teams autonomously organize their activities. Consequently, there are teams for books, textiles, electrical appliances or catering as well as teams responsible for support processes like taking care of parking space management, security, public relations, etc. In this regard, some NPOs (like parishes) can draw on existing sub-organizations (e.g., library team, women's group or youth organization). Social media are increasingly used to ensure (instant) communication between team members. However, a chief team leader or a steering group has to coordinate and monitor the teams. People holding such top management positions regard this task as burdensome, especially when the event is imminent:

“The last week before the flea market event takes place I can't sleep anymore because the mental wheel runs non-stop" (P12).

\subsubsection{Promotion}

Effective promotion and public relations are crucial for attracting visitors. The interviewees noted several communication channels like regional broadcasting and advertising in local and regional newspapers. Additionally, social media presence is increasingly important. An imaginative slogan raises attention and advances recognition. Promotion usually is more effective when a CFM is repeatedly organized; it then can acquire a core clientele keeping the usual date of the event in mind. Over the years, a CFM might establish itself as a brand.

\subsubsection{Storing capacities, waste disposal, and cooperation}

CFMs' operators organize the collection of goods either as a permanent process or at times in advance of market day. Especially the first option requires sufficient storing capacities. As soon as goods are collected, one has to consider their disposal. In some cases, donated goods are broken and unusable, and therefore have to be disposed. When goods of substantial value are not sold on market day(s), the NPO can only keep them for the next CFM if it can make use of an appropriate storehouse. Otherwise, the question arises to whom these goods could or should be transferred. In that regard, our interviewees cooperate with antique dealers, other flea market operators, and charities. Some directly transfer unsold goods to countries where purchasing power is relatively low (e.g., to Romania). In addition, for waste disposal cooperation with public and/or private waste disposal companies is a widespread option. The following statement illuminates how an operator utilizes the services of a private waste disposal company:

"We are lucky. I found a company. We just put textiles not for sale into bags and this company picks them up. (...) we get twenty cents per kilo (...) thus we don't just trash these goods into the dumpster" (P12). 


\subsubsection{Weather, atmosphere, and integration of fundraising instruments}

As many CFMs are (partly) organized outdoors, weather is a critical success factor. Weather conditions are "perfect" when weather is nice, i.e., it must neither be too cold or rainy nor too sunny and warm; otherwise, the number of visitors and their desire to buy will be negatively affected. On the contrary, lovely weather fosters a rush of visitors, contributes to an excellent atmosphere, and ensures buying mood. CFMs set themselves apart from other retailing institutions by a specific atmosphere. In this context, catering and other forms of entertainment are essential. Equally important is socializing enjoyed by both sellers and costumers. Meeting people, bargaining, talking to each other, playing and amusement as well as buying goods (one possibly does not really need) are part of the flea market experience. The following quotes shed more light on flea markets' unique atmosphere:

"People are looking for the ambience of the flea market (...) the flair of browsing, the flair of bargaining (...) this is an own atmosphere (...) they visit flea markets because they cannot find this feeling somewhere else" (P8).

"Online trading is no real competition (...) because of the whole atmosphere peculiar to the flea market experience" (P3).

CFMs allow for an integration of fundraising instruments. Several interviewees mention that not only gathering and selling in-kind donations as well as catering as a commercial activity are crucial for the market's success, but also sponsoring and entertainment facilities like raffles, auctions or charity concerts are employed as additional fundraising tools.

\subsubsection{Pricing and thefts}

The financial surplus generated at CFMs depends on the prices paid for products. Usually even well-preserved or relatively new objects are sold at very low prices. Prices are due to an individual bargaining process. Both commercial and benevolent dispositions affect most customers' willingness to pay. Nevertheless, certain customers and resellers sometimes try to haggle cheap prices down. For many visitors bargaining makes the appeal of a flea market purchase. However, if a customer attempts to negotiate prices grossly out of proportion to the value of the good, voluntary sellers conceive this behavior as a disregard of their commitment. Additionally, volunteers cannot make sense of the motives of stealing. Several interviewees spoke frankly about the serious problem of thefts:

"They thieve like a magpie (...) they steal everything" (P5).

"Many goods get stolen, it's terrible (...) they steal even though the surplus is dedicated to the animals [i.e., the good cause]. How can they dare to steal from animals?! It's incomprehensible to me" (P12).

\subsection{Benefits and perspectives}

All interviewees state that their CFMs do achieve financial goals and generate significant income representing a substantial contribution to balancing budgets or to (co-)finance investments in equipment and infrastructure. Expenditures for operating CFMs 
are comparatively low as premises can often be used free of charge and labor is voluntary. Other costs (e.g., for advertising) frequently are covered by sponsoring. Pro bono services provided by businesses are of importance, too. It is noteworthy that NPOs throughout assess CFMs' success by a purely cash-oriented calculation: interviewees consider only cash flows, but do not take into account resources available free.

Apart from financial benefits, they highlighted that CFMs are great fun and strengthen the community spirit:

"It's really fun for everybody; otherwise we wouldn't have such strong support of all these people running the market" (P4).

"It's also favorable to our community and its spirit (...) because on market days almost everybody is present and contributes (...) that's not the way it is at other times during the year" (P8).

Most respondents think that CFMs have a fair chance in the future, even if competition via second-hand shops, online auctions or e-commerce intensifies. Necessary to that end is enhancing their profile as unique events and offering enticing catering. Moreover, CFMs can provide a mental relief for donors who rather give their unwanted belongings to NPOs instead of throwing them away. The following quote illustrates the great potential of attracting in-kind donations in today's consumer society:

"Everybody has brim-full wardrobes. Flea markets are a good occasion to sort out things. I think it's somehow a psychological issue (...) because nobody likes throwing things away (...) Thus people donate their clothes to the flea market, and even if they cannot be sold and finally are disposed of anyway, they are out of sight and that settles the matter" (P10).

Nevertheless, all interviewees are aware of the fact that CFMs' perspectives depend on mobilizing enough volunteers, especially for carrying out time-consuming tasks. This is even more vital as many people are not willing to deliver their donations anymore, but expect NPOs to pick them up. If NPOs would have to pay staff, this would reduce the CFM's proceeds and could at worst render this fundraising practice useless. Consequently, some operators have already altered the frequency of their market (from annual to biennial) in order to avoid bleeding dry their volunteers. One final statement expresses a rather pessimistic view:

"I'm sure that the flea market is not everlasting, at least not in its present form (...) we have these elderly ladies and gentlemen who are in fact present day-today and sorting out things over several months (...) the young generation won't do that anymore. Commitment of that kind ceases" (P10).

\section{Discussion}

Both literature and interviewees stress the unique ambience and event character of (charity) flea markets. Visitors are not only attracted by bargains but also by the specific 
atmosphere and the opportunity of socializing. An additional motive (for visitors, volunteers, and other supporters) might be the need to meet social expectations of their local community. Especially in communities where "everyone knows everyone" there may be a pressure to contribute to this event, e.g., as a volunteer, sponsor or customer. Providing supplemental fundraising opportunities like donation boxes could exploit such a willingness to sustain the good cause (without urging people to amass belongings they do not want or need). Catering and other means of entertainment are consistently highlighted as crucial for setting CFMs apart from other retail forms. However, the question arises how CFM operators could find the right balance as exaggerating "professional" entertainment in terms of a commercialization might involve the risk of destroying the particular essence and flair of CFMs. Furthermore, catering and entertainment programs can trigger tax issues (depending on national legislation) and cause problems concerning the organizations' nonprofit status.

Operating CFMs requires mobilizing different resources (above all, in-kind donations and volunteering). Based on our findings, support via corporate philanthropy takes on an important but expandable role. Businesses provide money as well as noncash assistance and thereby contribute to the (financial) success of CFMs. NPOs could more systematically address (local) companies and try to persuade them of supporting their CFMs by corporate giving, sponsoring, and corporate volunteering. Aside from altruistic motivations for granting support, elevated expectations concerning corporate social responsibility might raise their disposition to demonstrate social and ecological commitment. In addition to intensifying private giving, volunteering, and corporate philanthropy, it seems worthwhile to develop government support. Local public authorities could also support CFMs or the operating NPOs (that often provide services for the public benefit). Based on our case studies, this opportunity so far is largely neglected. We are confident that CFMs might act as a catalyst to obtain other resources. According to Kearns et al. (2014) certain types of funding can produce positive spin-offs "by generating not only other types of funding, but also other valued resources like visibility in the community or partnerships" (p. 136). We regard CFMs as a cross-sectoral fundraising practice which could simultaneously harness resources stemming from corporations, public institutions, and civil society and foster community building (within the NPO and its region).

Individual in-kind giving currently represents CFMs' main source of assortment. It seems likely that this primacy will continue as many consumers accumulate vast amounts of objects and often are faced with the dilemma of neither wanting to keep nor wanting to throw away their excess belongings. Besides, values in terms of sustainable development are gaining influence. Nevertheless, previous studies show that donors of used merchandize are not primarily motivated by altruism but by self-interest. Insofar operators of CFMs should deliberately address donors' needs to clear out their homes, offer convenient and visible dropoff locations (like the aforementioned "bag drops") in times of spring-cleaning, and arrange pick-up of donations. Partnerships with recycling yards and house (or office) clearance services could be useful, too.

Such efforts on improving donation activity are coupled with a fundamental condition. Our findings clearly point to the significance of volunteers for the success of CFMs and NPOs' ability to process product donations. Without their assistance, the value of second-hand retail to the financial viability of a nonprofit cannot be preserved. 
With regard to the shell model of volunteering in CFMs (cf. figure 2) it seems essential that volunteers could vary their type of commitment. On the one hand, an episodic volunteer could gather experience by recurrent activities for management tasks. Besides, he or she might then identify (more) with the NPO and its objectives. This could create motivation to support the NPO in other contexts apart from the CFM. On the other hand, members of a steering group could temporarily engage in less demanding commitments. By varying the intensity of commitment (i.e., switching between the different types or shells), volunteers can align their contribution to their current life situation and needs. Enabling variation could help prevent overload of single volunteers. It remains unclear whether a crowding out effect exists. It might be that voluntary work in the context of CFMs possibly replaces other mission-directed activities valuable to NPOs.

\section{Conclusion}

Previous research on flea markets is scarce and focused on settings characterized by numerous individual vendors pursuing their goals. Thus, to the best of the authors' knowledge, this is the first paper investigating such marketplaces as a fundraising practice of NPOs. Our study adds to prior research on nonprofits' resource management by integrating existing knowledge of charity shops and (conventional) flea markets, and by our empirical study exploring ten Austrian CFMs. As one result, we derive the following working definition from both our cross-disciplinary literature review and our case study findings:

A charity flea market is a second-hand market (indoor and/or open-air) organized by a single NPO in order to raise funds for supporting their purposes. Therefor a NPO pools resources from individual and corporate in-kind giving and volunteering in an unique event setting. With the assistance of volunteers product donations of all kinds are collected in advance, and then volunteers resell this donated merchandise to flea market visitors looking for alternative shopping experiences, deals and bargains as well as social interaction. In order to attract customers and to create a diverting atmosphere they typically provide a custom-tailored entertainment program including food sales as a further means of generating cash.

Goods offered and sold at CFMs typically comprise a variety of used household items, clothes, recreation-oriented products like toys or sports goods, jewelry, small furniture and other objects. Most in-kind donations stem from individuals, but half of the CFMs analyzed rely on corporate giving, too. The consumer base is heterogeneous concerning age, gender, social class, income, and visitors' cultural, ethnic, and occupational background. Collectors and antique dealers are outstanding customer groups besides locals and tourists.

We identified a range of challenges and critical success factors specific to operating CFMs. These relate, on the one hand, to exogenous variables like the weather or - to some extent - the quantity and quality of received product donations. On the other hand, market operators can influence factors like, e.g., the integration and alignment of 
their structures, processes, and fundraising activities; their efforts concerning effective promotion as well as internal coordination and external cooperation; appropriate handling of the widespread problem of theft; arrangements for collecting and storing goods permanently; or maintaining the special atmosphere of CFM settings.

The interviewed CFM operators highly appreciate the surplus generated by selling in-kind donations and food with the help of their volunteers, as well as the benefits for community building that go along with such events. Altogether, most interviewees favorably assess the perspectives of this fundraising practice. However, our findings point to two challenges that are vital for its future viability. First, receiving rising quantities of unusable goods ("junk") as well as a general decline in quality of in-kind donations (because of the popular trend to make money out of unwanted possessions via online auctions or trade platforms) pose risks for NPOs. Loads of assortment of worthy and nonmarketable goods require sorting which takes time and effort and could possibly overstrain volunteers. Besides, the necessity to look for possible outlets of unsalable goods or to dispose of them increases complexity of logistics and involves transportation and disposal costs. In order to counter these issues, we recommend more cross-sector cooperation: namely between NPOs and other NPOs (e.g., operators of charity shops and other CFMs or fundraising intermediaries specialized on product philanthropy); additionally, between NPOs and companies being open-minded about corporate in-kind giving and corporate volunteering. In this regard, we also suggest approaching local producers of food or beverages or supermarkets and asking for product donations useful for CFM catering. Finally, NPOs may address public institutions as so far widely neglected supporters (e.g., free use of public real property) or in-kind donors (e.g., in times of relocation they dispose of goods). We believe that practitioners could widen their collaborative perspective and that striking new, perhaps unorthodox paths could be a key to intensifying targeted in-kind giving and a promising means to obtain needed, (more) valuable and highquality in-kind donations. Although (in-kind) donations by private citizens are important, CFM operators should target other donor groups as well and benefit from private, corporate and public philanthropy at once.

Second, meeting the challenge of sustaining volunteering is an Achilles' heel for both the future of CFMs and many NPOs in general. Returning a profit depends on sufficient support of volunteers. While most CFM operators have no issue with gathering enough episodic volunteers for the actual market days, it gets exceedingly difficult to motivate people to engage themselves on a regular, long-term and continuous basis (essential for gathering, sorting, and refurbishing goods). Against this background, we suggest a further takeaway of interest to practitioners related to activating volunteers. As issues like environmental protection, recycling goods, reducing food waste or climate protection are gaining attention and acceptance in contemporary consumer societies, NPOs could emphasize such motives when recruiting (especially young) volunteers. The rising awareness in terms of sustainability and corporate social responsibility could be a "fertile soil" for the future of second-hand markets. If NPOs succeed in seizing this opportunity, organizing CFMs could facilitate addressing, motivating, and binding new volunteers as well as sustaining current and winning back former supporters (like volunteers, donors, sponsors, etc. who are interested in social and ecological causes). 
We acknowledge that our investigation has several limitations. Of course, the limited sample of ten case studies does not permit us to propose generalizations of our findings beyond the discrete group of CFM operators we interviewed. In addition, social desirability bias is an issue to be considered when interpreting our findings. However, the rich qualitative material collected during this explorative study provides a valuable starting point for future research. First, our study could be replicated in other regions or countries to evaluate the transferability of the findings reported here and to explore possible regional variations, and in order to put forth some testable propositions for future research. Second, it seems worthwhile to broaden the perspective and investigate the views, experiences and motivations of the manifold stakeholders involved in CFMs (like, e.g., different groups of donors, volunteers, cooperation partners, and CFM visitors). Third, future research would need to identify suitable solution approaches to the manifold challenges identified. Further field research on ("successful") CFMs could possibly reveal best practices with regard to, e.g., processing in-kind donations or managing und sustaining voluntary work as well as cross-sectoral cooperation. Fourth, the theoretical and practical question of how NPOs could adequately balance their multiplex stakeholder relations and resource dependencies requires further investigation, especially in the underexplored context of product philanthropy. Finally, our findings could be the basis for designing a traditional survey questionnaire administered to a large cross-section of stakeholders involved in CFMs. Such an analysis could - among many other meaningful endeavors - pursue the questions of why and under which circumstances different groups of volunteers as well as donors are willing to support NPOs organizing CFMs. It remains to be seen whether the growing ecological awareness will be a driver for such alternative marketplaces. From the authors' point of view, promoting CFMs as well as other second-hand markets could at least be a piece in the puzzle towards a more sustainable future.

Acknowledgements The authors would like to thank the anonymous reviewers for their helpful and constructive comments that contributed to improving the article.

Funding information Open access funding provided by Johannes Kepler University Linz. The authors received no financial support for the research, authorship, and/or publication of this article.

\section{Compliance with ethical standards}

Conflict of interest The authors declare that they have no conflict of interest.

\section{Appendix: Guiding questions}

1) For how long are you working for this organization? What are your responsibilities?

2) How often do you organize flea markets and what is their purpose?

3) What are specific challenges and key success factors for organizing a CFM? Which people with what kind of talents and skills are necessary to do so?

4) Who are typical donors and clients? What kind of people and/or organizations donate goods? What kind of people buy these goods? 
5) What kinds of goods are donated most frequently? Have in-kind donations changed during the past years? Do some donors use their contributions as a way to dispose of their waste?

6) What do you do with donated goods that cannot be sold?

7) What tasks, efforts, and expenditures are necessary for organizing a CFM? If you relate inputs to outputs: Does it pay off to organize a CFM?

8) How important are CFMs as a fundraising instrument in general? Moreover, which role in particular plays the flea market for your organization compared to your other sources of funding?

9) How do you assess the future prospects of CFMs?

Open Access This article is licensed under a Creative Commons Attribution 4.0 International License, which permits use, sharing, adaptation, distribution and reproduction in any medium or format, as long as you give appropriate credit to the original author(s) and the source, provide a link to the Creative Commons licence, and indicate if changes were made. The images or other third party material in this article are included in the article's Creative Commons licence, unless indicated otherwise in a credit line to the material. If material is not included in the article's Creative Commons licence and your intended use is not permitted by statutory regulation or exceeds the permitted use, you will need to obtain permission directly from the copyright holder. To view a copy of this licence, visit http://creativecommons.org/licenses/by/4.0/.

\section{References}

Anheier, H. K. (2014). Nonprofit organizations: Theory, management, policy (2nd ed.). London/New York: Routledge.

Appelgren, S., \& Bohlin, A. (2015a). Introduction: Circulating stuff through second-hand, vintage and retro markets. Culture Unbound - Journal of Current Cultural Research, 7, 3-11.

Appelgren, S., \& Bohlin, A. (2015b). Growing in motion: The circulation of used things on second-hand markets. Culture Unbound - Journal of Current Cultural Research, 7, 143-168.

Bianchi, C., \& Birtwistle, G. (2012). Consumer clothing disposal behaviour: A comparative study. International Journal of Consumer Studies, 36, 335-341.

Chattoe, E. (2000). Charity shops as second-hand markets. International Journal of Nonprofit and Voluntary Sector Marketing, 5(2), 153-160.

De Bruin, A., \& Dupuis, A. (2000). The dynamics of New Zealand's largest street market: The Otara flea market. International Journal of Sociology and Social Policy, 20(1/2), 52-73.

Duffy, K., \& Hewer, P. (2013). The Vintagescape as embodied and practiced space. Advances in Consumer Research, 41, 350-354.

Gazley, B., \& Abner, G. (2014). Evaluating a product donation program. Challenges for charitable capacity. Nonprofit Management and Leadership, 24(3), 337-355.

Gray, C. M. (2007). Gifts-in-kind and other illiquid assets. In D. R. Young (Ed.), Financing nonprofits. Putting theory into practice (pp. 227-241). Lanham: AltaMira Press.

Hansson, N., \& Brembeck, H. (2015). Market hydraulics and subjectivities in the "wild": Circulations of the flea market. Culture Unbound - Journal of Current Cultural Research, 7, 91-121.

Horne, S., \& Maddrell, A. (2002). Charity shops. Retailing, consumption and society. London/New York: Routledge.

Hustinx, L. (2005). Weakening organizational ties? A classification of styles of volunteering in the Flemish red cross. Social Service Review, 79(4), 624-652.

Islam, M. M. (2013). In-kind donation practices, challenges and strategies for NGOs and donors, Doctoral Thesis, Georgia Institute of Technology. https://smartech.gatech.edu/bitstream/handle/1853/50332 /ISLAM-DISSERTATION-2013.pdf?sequence=1\&isAllowed=y. Accessed 12 December 2015.

Kearns, K. P., Bell, D., Deem, B., \& McShane, L. (2014). How nonprofit leaders evaluate funding sources: An exploratory study of nonprofit leaders. Nonprofit and Voluntary Sector Quarterly, 43(1), 121-143. 
Krippendorff, K. (2013). Content analysis. An introduction to its methodology (3rd ed.). Thousand Oaks: Sage Publications.

Lee, E. J. (2015). A case study on motivation and constraints of corporate product philanthropy. Indian Journal of Science and Technology, 8(18), 1-7.

Lienbacher, E. (2013). Corporate Social Responsibility im Handel. Diskussion und empirische Evidenz des alternativen Betriebstyps Sozialmarkt. Wiesbaden: Springer Gabler.

Lovatt, M. (2015). Charity shops and the imagined futures of objects: How second-hand markets influence disposal decisions when emptying a Parent's house. Culture Unbound - Journal of Current Cultural Research, 7, 13-29.

Mayring, P. (2010). Qualitative Inhaltsanalyse (11th ed.). Weinheim/Basel: Beltz Verlag.

Mhango, M. W., \& Niehm, L. S. (2005). The second-hand clothing distribution channel. Opportunities for retail entrepreneurs in Malawi. Journal of Fashion Marketing and Management, 9(3), 342-356.

Mitchell, M., Montgomery, R., \& Rauch, D. (2009). Toward an understanding of thrift store donors. International Journal of Nonprofit and Voluntary Sector Marketing, 14, 255-269.

Montgomery, R. D., \& Mitchell, M. (2014). Examining the demographic profiles of thrift store donors and thrift store shoppers. Atlantic Marketing Journal, 3(1), 1-13.

Petrescu, M., \& Bhatli, D. (2013). Consumer behavior in flea markets and marketing to the bottom of the pyramid. Journal of Management Research, 13(1), 55-63.

Ross, J. M., McGiverin-Bohan, K. L. (2012). The business case for product philanthropy, Indiana University, School of Public and Environmental Affairs. http://www.nchv.org/images/uploads/The_Business_Case_ for Product Philanthropy WEB(1).pdf. Accessed 6 November 2017.

Roux, $\bar{D} .$, \& Guiot, D. (2008). Measuring second-hand shopping motives, antecedents and consequences. Recherche et Applications en Marketing, 23(4), 63-94.

Scitovsky, T. (1994). Towards a theory of second-hand markets. KYKLOS, 47, 33-52.

Shearer, R., \& Carpentier, K. (2015). Determining the optimal donation acceptance policy for nonprofit stores. Nonprofit Management \& Leadership, 26(1), 59-71.

Sherman, E., McCrohan, K., \& Smith, J. D. (1985). Informal retailing: An analysis of products, attitudes, and expectations. Advances in Consumer Research, 12, 204-208.

Sherry Jr., J. F. (1990a). A sociocultural analysis of a Midwestern American flea market. Journal of Consumer Research, 17(June), 13-30.

Sherry Jr., J. F. (1990b). Dealers and dealing in a periodic market: Informal retailing in ethnographic perspective. Journal of Retailing, 66(2), 174-200.

Smith, D. H., Stebbins, R. A., Grotz, J., Kumar, P., Nga, J. L. H., \& Puyvelde, S. (2016). Typologies of associations and volunteering. In D. H. Smith, R. A. Stebbins, \& J. Grotz (Eds.), The Palgrave Handbook of Volunteering, Civic Participation, and Nonprofit Associations, volume 1 (pp. 90-125). Hampshire/New York: Palgrave Macmillan.

Watt, K., \& Dubbeld, B. (2016). Enchanting the worn-out: The craft of selling second-hand things at Milnerton market, Cape Town. Social Dynamics, 42(1), 143-160.

Yin, R. K. (2018). Case study research and applications: Design and methods (6 ${ }^{\text {th }}$ ed.). Los Angeles: Sage.

Publisher's note Springer Nature remains neutral with regard to jurisdictional claims in published maps and institutional affiliations. 